\title{
La villa romana de la Salut de Sabadell y su complejo termal
}

\author{
Gregorio López Pérez
}

El Santuario de la Mare de Deu de La Salut y jardines circundantes, forman la parte urbanizada de la sierra de Sant Iscle, situada a levante de los rios Ripoll y Tort o Riutort, flanqueada por la carretera a Caldes de Montbui (Via Augusta).

Como en tantos otros lugares, en los trabajos agricolas aparecieron restos de objetos de cerámica: ánforas, doliums, tegulae, etc., así como piedras labradas e indicios de paredes que probaban la existencia de antiguas edificaciones.

Bajo los auspicios de Don Joan Vila Cinca dio comienzo a la primera etapa de las excavaciones en 1912-1916. A ésta siguieron dos más, 1931-135 y la última en 1948, ambas bajo la dirección de don Vicente Renom. Posteriormente se han realizado algunas catas aprovechando obras de mantenimiento o reparación. Las excavaciones proporcionaron abundante material, conservado actualmente en los Museos Arqueológico de Barcelona e Histórico de Sabadell.

Estos hallazgos se consideraron como pertenecientes a un poblado ibero romano, con tres etapas bien diferenciadas, una ibérica, otra con influencia romana y una tercera menos importante, pero que perduró hasta la Edad Media.

La afirmación de que este asentamiento fue la base del actual Sabadell, choca con las opiniones de diversos especialistas: Morral y Llobet (1976) presentaron en una reunión de estudiosos que tuvo lugar en el Museo de Historia de Sabadell una sesión ilustrada con diapositivas en la que definieron los restos de La Salut como correspondientes a una villa rústica de grandes dimensiones, no anterior a la primera mitad del siglo 1 a.C., pero sin excluir leves indicios republicanos.

A fin de dar una mayor información respecto a este problema, he recogido abundante documentación sobre las ánforas y sigillata de pro- 
ducción local, así como hallazgos de aproximada contemporaneidad en lugares cercanos, más en este caso, en que nada más se conserva el material mobiliario y las estructuras permanecen enterradas o han desaparecido totalmente.

Los asentamientos ibéricos vallesanos, fuera de Torre Roja (Sentmenat) se componian de cabañas no agrupadas y su utillaje lo formaban cerámica gris o bicolor y como material exótico, la campaniense A y B, faltando el tipo helenístico.

Berardo o Castell Arnau (Sabadell) es un ejemplo típico, toda vez que, al lado de restos romanos, se encontraron cabañas y un par de inhumaciones, una con tegulae y otra con piedras. Durante las obras de urbanización se abrieron una red de calles y en los márgenes de las mismas aparecieron restos de cerámica ibérica y romana.

El topónimo Arragona o Arrahona, que ha perdurado durante siglos, se cita por primera vez en el itinerario de Gades a Roma, en uno de los Vasos Apolinares encontrados en Las Termas de Vicarello (Italia), donde se arrojaban como agradecimiento por haber regresado sano y salvo del viaje. Este nombre no parece pertenecer a un reducido número de cabañas, más bien correspondería a un lugar geográfico, riachuelo, fuente o a un asentamiento más importante, no localizado hasta la fecha.

La Salut en los niveles ibéricos presenta campaniense $A$ y $B$, que nos da una fecha entre el fin del siglo iv a finales del III a.C., como cifra inicial y que perduraria hasta últimos del siglo ॥/inicios del I a.C.

La villa de Arragona tuvo cierta importancia, como se demuestra al estar incluida dentro del itinerario de los Vasos Apolinares. Tendría a más de una importante producción agraria, una potente industria ceramista, tanto de tipo anfórico (CASAS Selvas 1987), como de sigillata Roca Romens 1978). A más, parte de su complejo urbanístico podría haber estado destinado para alojamiento y lugar de descanso de los viajeros.

Los puntos 11, 14, 21 y 23 del plano adjunto es muy posible formen parte de un complejo termal, correspondiente al periodo de mayor esplendor de la villa. El punto 11, al paseo central, corresponde a una conducción o desagüe, protegida con paredes y con pavimento o solera y cubierta con ladrillos de $40 \times 40 \mathrm{~cm}$. Conectaba con un depósito por medio de una tuberia de plomo, con una plataforma sujeta por medio de clavos, a fin de evitar la pérdida de líquido. Este depósito tenía tres escalones para descender al fondo, compuestos de fragmentos cerámicos, piedras y mortero, el clásico opus testaceum. Su misión era proveer de agua al complejo termal, cuya conducción entre los puntos 14 y 23, posiblemente llegaba a un fornex, que a más de calentarla, lo hacía 
con el aire que pasaba por el hipocaustum y suspensura, hasta el punto 21. En este punto (edificio absidiado), la parte más caliente de todo el conjunto, sería el laconicum o lugar para tomar baños de vapor; a su lado (edificio cuadrado), estaria el caldarium y en los puntos 14 y 23, el frigidarium, con un baño a cada uno de ellos. El depósito (11) podría utilizarse como piscina para bañarse en verano, con el agua temperada por el calor atmosférico.

Estas termas podrían estar pensadas para posible uso de viajeros o clientes. Las de servicio para los propietarios de la villa, están relacionadas con el mosaico de Neptuno y otros puntos próximos. También podria tratarse de una readaptación de la villa después del ataque de francos y alamanes y la crisis a la que se vio sometida (siglo III). La ausencia de cenizas anotada en el diario de las excavaciones asi lo hace suponer.

Los puntos $12,15,16$ y 18 son los relacionados con estas termas privadas. El punto 12 corresponde a un depósito con desagüe y varias dependencias localizadas al lado de la iglesia antigua. En estas excavaciones aparecieron entre otros objetos las primeras teselas de mosaico y fragmentos de finas losas de mármol. El punto 15 proporcionó el mosaico bicromo de Neptuno, que figura en un excelente estudio (BARRAL 1978). El opus tesellatum está confeccionado con teselas blancas y negras de $1 \times 1 \mathrm{~cm}$. El caso curioso es la representación de Neptuno, como si se tratase de una estatua, alejada de la temática romana, acercándose más a la griega o helenística. Su antigüedad se calcula entre los siglos $I 1$ y 111 d.C. Los puntos 16 y 18 dieron más teselas, un trozo de mármol con los bordes redondeados y la continuación de la conducción o desagüe (12).

Las termas de Can Tarrés (La Garriga), por su proximidad y contexto, parecen tener cierta similitud (PASCUAL 1977) con las de La Salut. Las mismas tienen un frigidarium, con acceso por un patio descubierto. En la parte oeste del frigidarium hay otra piscina más grande que la anterior y con tres escalones. Estas dependencias comunican con una serie de departamentos, dos con planta absidial y otra cuadrada. Todas estuvieron provistas de hipocausto o suspensura. El aire caliente procedía de un fornax, situado al pie de la forma absidial mayor, posiblemente el laconicum. El caldario daba paso al tepidarium o lugar temperado, donde los bañistas se preparaban para pasar al frigidarium.

Las termas de Els Munts (Berges 1970), conjunto cercano al mar, son de una mayor riqueza, con placas de mármol y mosaicos.

En Vilallonga del Camp (Tarragona) hay una construcción de planta absidiada (DUPRÉ y JULIÁ 1984), con un segundo ábside y un canalón que perfora transversalmente el muro sur. A pesar de que la técnica cons- 
tructiva puede corresponder tanto a unas termas como a una edificación paleocristiana, los dos ábsides y el canalón parecen hacer más posible lo primero.

La villa romana de Torre Llauder (Mataró) (RIBAS 1970) cuenta como la de La Salut con termas y baño privado, este último con mosaico. Estos datos nos dan unas similitudes muy notables. Conjuntamente con La Torre Llauder, se excavó también un suntuoso edificio romano dentro del recinto antiguo de Mataró, con piscinas y mosaicos. La llamada Domus Natalis.

Durante el transcurso de las excavaciones de las termas de La Salut apareció entre otros objetos uno en forma de disco, de $8 \mathrm{~cm}$ de diámetro por 3 de grueso, provisto de tres agujeros. Inicialmente se creyó podria tratarse de un nuevo tipo de pondus. Esta pieza recuerda a otra recogida superficialmente por los alrededores de los restos de la villa de Can Bonvilá (Terrassa). Se trata también de un objeto en forma más o menos circular (LÓPEZ 1992) de unos $7 \times 3 \mathrm{~cm}$ con un agujero al centro. Este objeto, junto con otros, se consideraron como integrantes de una conducción o desagüe. El tubo cerámico, de los llamados tubuliis, se acostumbraba a emplear en el desagüe de las piscinas de las termas. El hecho de tratarse de un hallazgo superficial no aconsejaba el definirlo como a tal, por parecer demasiado arriesgado que una sola pieza atestiguase la existencia de unas termas. Pero la coincidencia con el disco de La Salut incide en la duda. Todo está pendiente a la espera de que se realicen exhaustivas excavaciones.

La utilidad de estos discos podría estimarse fuera la de permitir o impedir el paso del agua en determinada dirección, a la manera de las arquetas de las castella domestica, para el suministro a los abonados de las poblaciones. Según se empleasen discos perforados o sin perforar, o taponando alguno o algunos de los agujeros. Según Vitrubio (FERNÁNDEZ CASADO 1983), en su libro VIII, capítulo VII, "Las diferentes maneras de conducir el agua", nos habla entre otros del sistema que vemos empleado en La Salut (solera, paredes y cubierta), para evitar las impurezas y el recalentamiento por el sol ut minime sol aqua tangat.

Como colofón, podría considerarse a Arragona o Arrahona como una villa exclusivamente romana, los restos ibéricos, corresponden a núcleos dispersos, cabañas más o menos aisladas. Es muy posible que en un momento dado coincidiesen ambas culturas, no para constituir un ente mixto, sino, como personal auxiliar en la construcción de la villa o mano de obra en el mantenimiento de las instalaciones y las diversas áreas de producción de la misma. Estas funciones estarian a cargo de los iberos y personal esclavo, bajo la dirección de los romanos. 


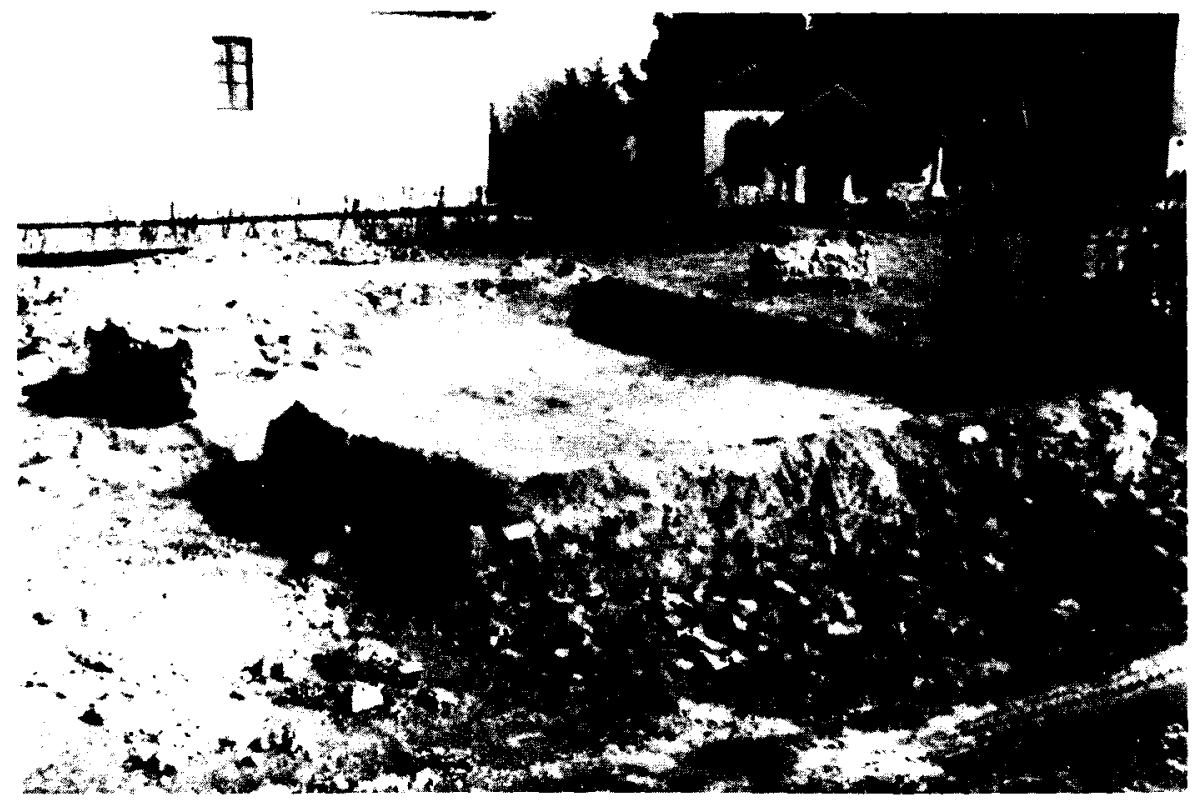

Excavaciones de la villa romana de La Salut. Depósito o piscina $\left(n^{\circ} 11 \mathrm{del}\right.$ plano).

La antigüedad como a tal de la villa se habría de remontar a la primera mitad del siglo । d.C., de acuerdo con los datos de los hornos y del tipo de producción. Con la sigillata hispánica autóctona, vemos que la producción da comienzo a la segunda mitad del siglo I, hasta principios del II. Con las ánforas, se alarga esta fecha hasta finales del III y principios del IV.

La producción de ánforas del tipo layetana y la aparición de la forma Pascual I coincide con la crisis sufrida por la falta de exportación de vino, quedando reducida al consumo interior. También es factor a tener en cuenta el crecimiento experimentado por la ciudad de Mataró, que recogió la importancia que tuvo Burriac, incluido su nombre de lluro o Ilduro. Este hecho revalorizó la rama costera de la Vía Augusta, en detrimento de la interior que pasaba por Arragona.

La destrucción producida en el siglo $\|$ d.C. por la invasión de fran$\cos$ y alamanes, que produjo el abandono de muchas villas, unida a la 


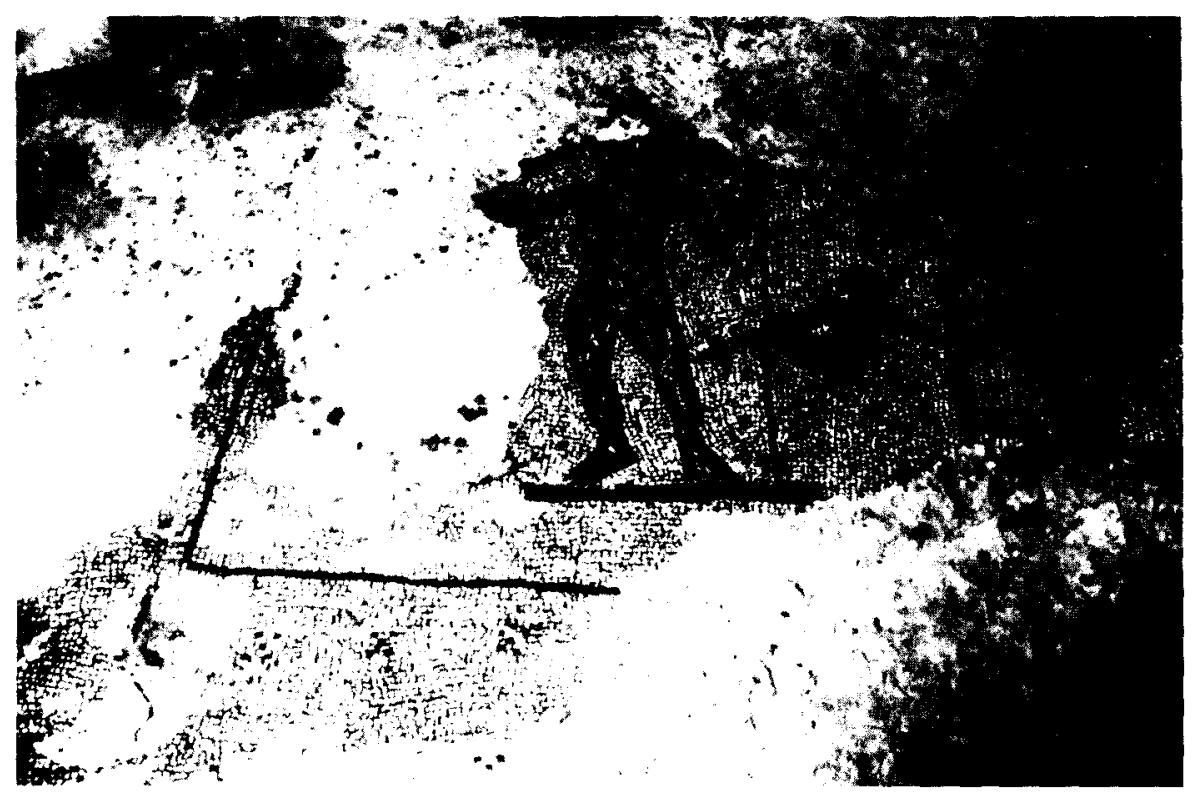

Excavaciones de la villa romana de La Salut.

crisis de los Severos, que produjo la ruina de gran parte del sector productivo: minas, garum, devaluación de la moneda, etc., fueron minando la importancia de La Salut, que a pesar de perdurar hasta la Edad Media, habria quedado reducida a una simple casa de labranza.

Un par de lápidas procedentes de este antiguo aseritamiento fueron rescatadas de un muro de la capilla de Sant Nicolau, último vestigio de la antigua iglesia de Sant Feliu de Arrahona. Otros restos podrian haber estado al Castillo de Arrahona, pero de éste ya no quedan ni los cimientos.

Como la población se iba instalando en el llano, en el siglo xi se fundó (1076) la capilla de Sant Salvador y con el tiempo (1373) se instaló la nueva parroquia de Sant Feliu de Sabadell. El núcleo urbano se fue formando alrededor de un mercado. El lugar céntrico y estratégico hizo que muchos investigadores opinasen que Arragona estaria situada en este lugar (cruce de los caminos de Barcelona a Manresa y Caldes a Sant 


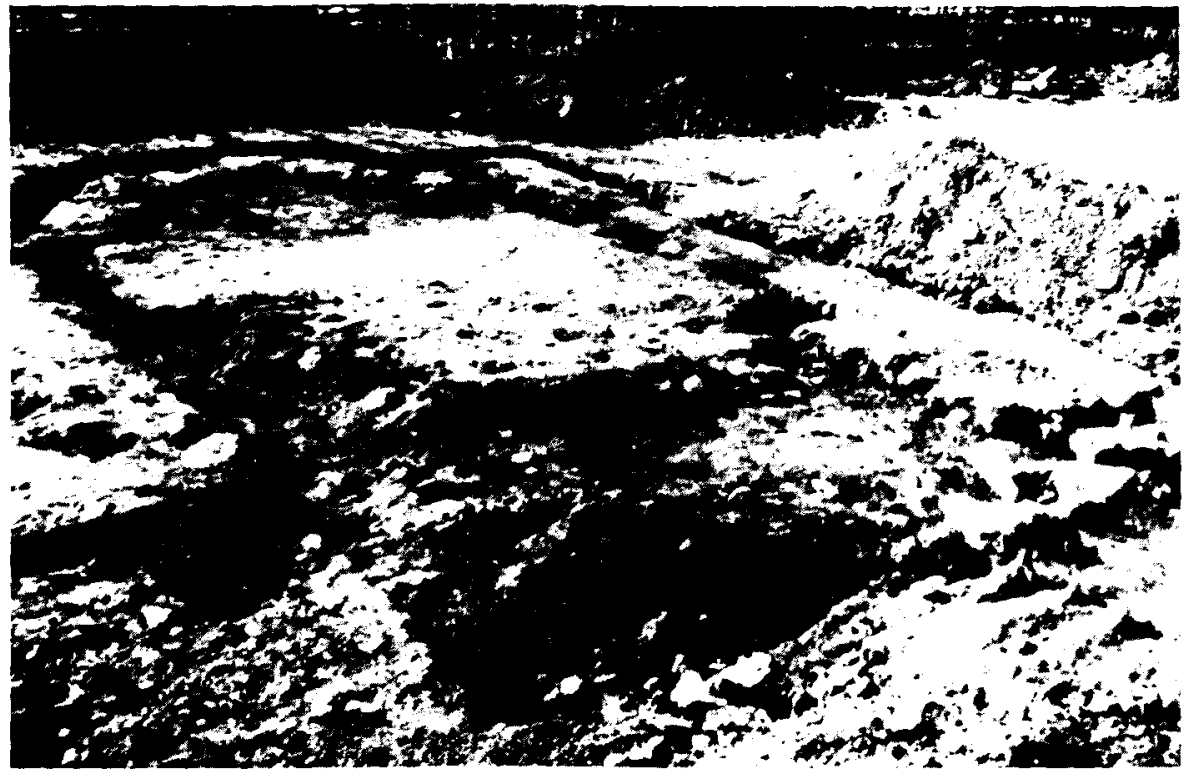

Excavaciones de la villa romana de La Salut. Edificio absidado $\left(n^{\circ} 21\right.$ del plano

Cugat) (SERRA RÁfols 1962). Este es el forum Sabadelli de que habla un documento del 1111.

Es un muy probable que posteriores excavaciones que puedan realizarse en el subsuelo del Santuario de La Salut o en su entorno puedan confirmar o aclarar si este establecimiento fue o no la cuna de Sabadell.

\section{BIBLIOGRAFIA}

BARBERA, J. (1970): "Una cata estratigráfica a Burriac", Información Arqueológica, núm. 3 , págs. 94-96.

BarRal Altet, J. (1978): “Les mosaiques romaines et médiévales a la Regio Laietana». Universidad de Barcelona, págs. 136-138.

Beltrán LloRis, M. (1976): Cerámica Romana. tipologia y Clasificación, Libros Pórtico.

Berges, P.M. (1970): "Las ruinas de "Els Munts", Altafulla (Tarragona)", Información Arqueológica, núm. 3, págs. 81-87.

CASAs Selvas, M.T. (1987): "Les ànfores de la vil.la de La Salut", Arrahona, núm. 1, págs. 15-16. 
DUPRÉ, J., y JULIA, M. (1984): "Un edifici de planta basilical a Vilallonga del Camp (Tarragona)", Información Arqueológica, núm. 42, págs. 58-61.

Fernandez CASAdo, C. (1983): Ingeniería Hidráulica Romana, Colegio Ingenieros de Caminos, Canales y Puertos, Ed. Turner, Madrid.

IbAÑez, G., y Martinez, A. (1991): Sitges ibero-romanos a la base oriental del Poblat lbèric de Puig Castellar. Santa Coloma de Gramenet (Barcelona).

LoPez Perez, G. (1992): “Troballes superficials a la vil.la romana de Can Bonvilà de Terrassa", Centre d'Estudis de la Natura del Barcelonés Nord, Quaderns de la Natura $i$ de l'Home, págs. 39-41.

Mangas ManjarRes, J. (1982): "Hispania Romana", Historia de España de Historia 16, Madrid.

MoRRAL, E., y LLOBET, C. (1976): “Visita cientifica a Sabadell», Información Arqueológica, núms. 20-21, págs. 61 .

Monografias del Museo Arqueológico Nacional, núm. 2, 1983, Madrid, T.S.H. Terra Sigillata Hispánica.

Pascual Guasch, R. (1970): “La Tabla de Dressel”, Información Arqueológica, núm. 1, págs. 5-7.

- (1977): "Les Termes de Can Tarrés (La Garriga)", Información Arqueológica, núm. 25, págs. 207-209.

Revista del Museo de la Ciudad (Sabadell), 1950, núms. 1-2, págs. 93-118.

Ribas Beltrán, M. (1970): "La excavación arqueológica de la villa romana de la Torre Llauder de Mataró", Información Arqueológica, núm. 1, págs. 19-21.

Roca Roumens, M. (1978): «Producció de sigil.lata a la vil.la de La Salut», Arrahona, núm. 6, págs. 1030.

Serra RAfols, J.C. (1962): A la memoria de D. Vicente Renom Costa. Sabadell, págs. 11 14.

\section{AGRADECIMIENTOS}

Agradezco sinceramente al profesor don Eduardo Ripoll Perelló, por los consejos y orientaciones recibidos en todo momento. Agradezco también las facilidades otorgadas por el Museu de Historia de Sabadell, especialmente por su conservadora la Srta. Roser Enrich, al permitirme consultar el diario de las excavaciones y otra documentación. Asimismo, al Archivo Histórico de Sabadell, que me ha proporcionado copias de las fotografias que ilustran este texto. Así como a mi hijo, por la reproducción de los dibujos anexos. 


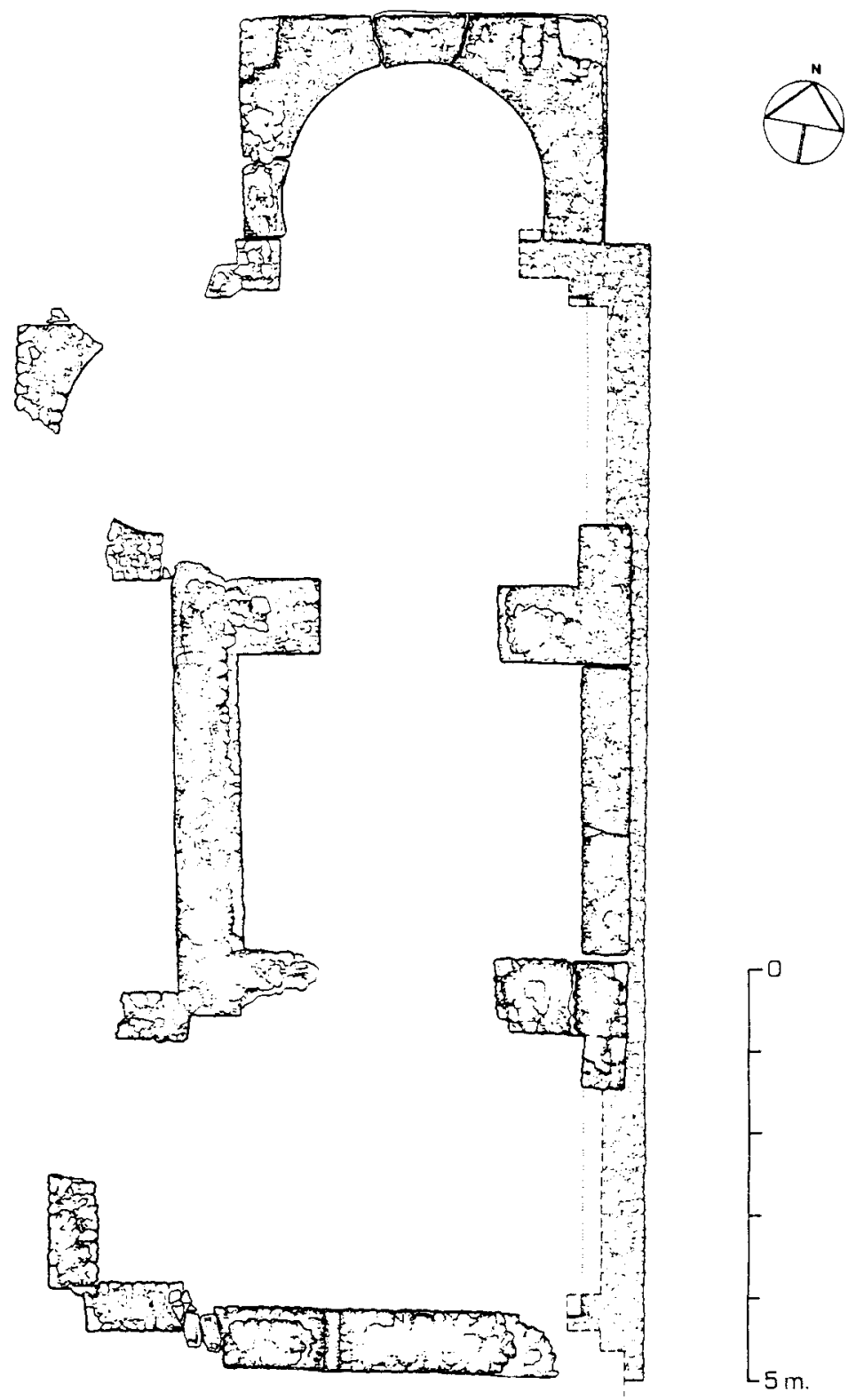

Villallonga del camp.-Edificio de planta absidiada con un segundo ábside al Oeste y un canalón al muro Sur. 


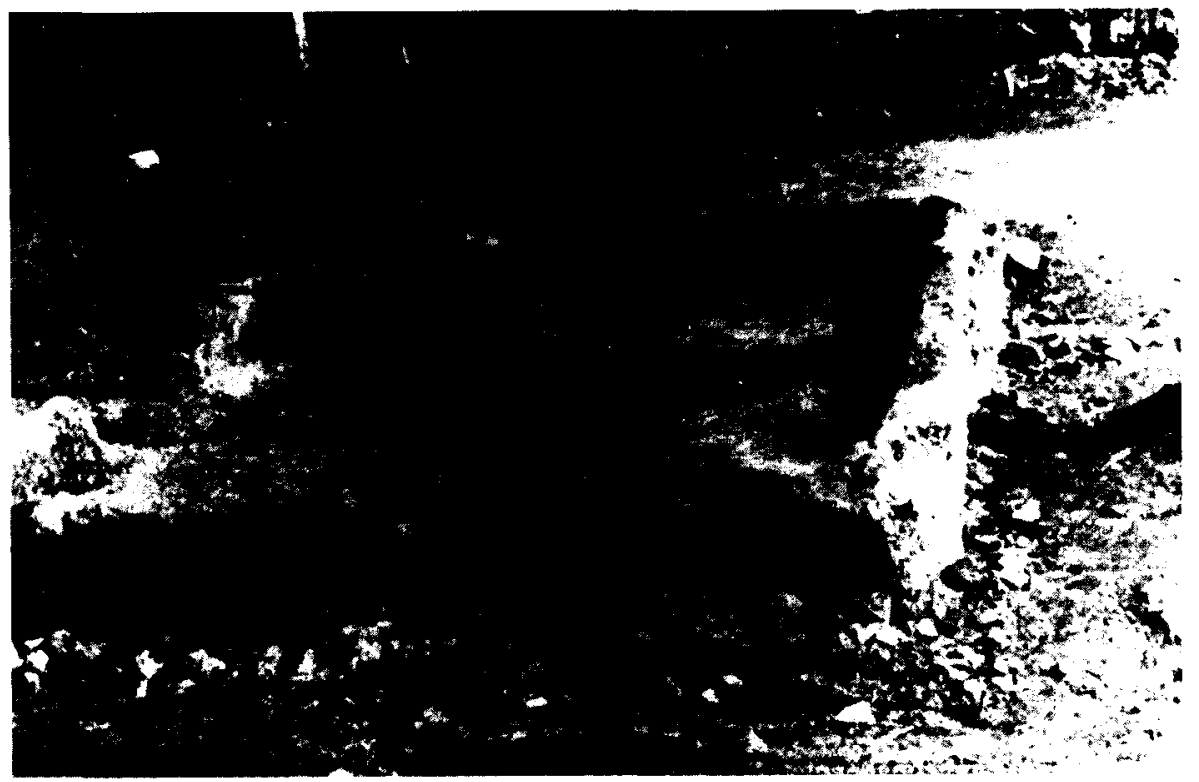

Depósito o piscina (núm. 11) del plano. (V. Renom y L. Mas, 1950). Probable complejo termal Villa romana de La Salut (Sabadell).

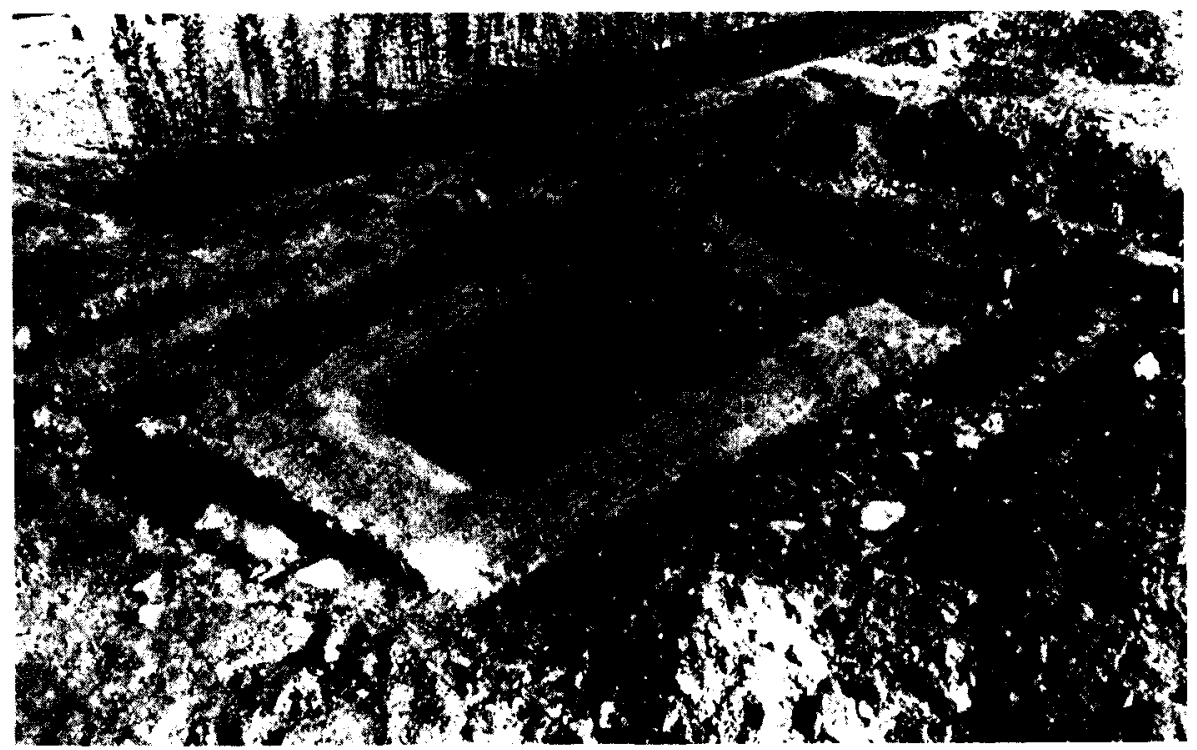

Depósito (num. 23) del plano, posiblemente utilizado como "frigidarium". (V. Renom y L. Mas, 1950).

Probable complejo termal Villa romana de La Salut (Sabadell). 


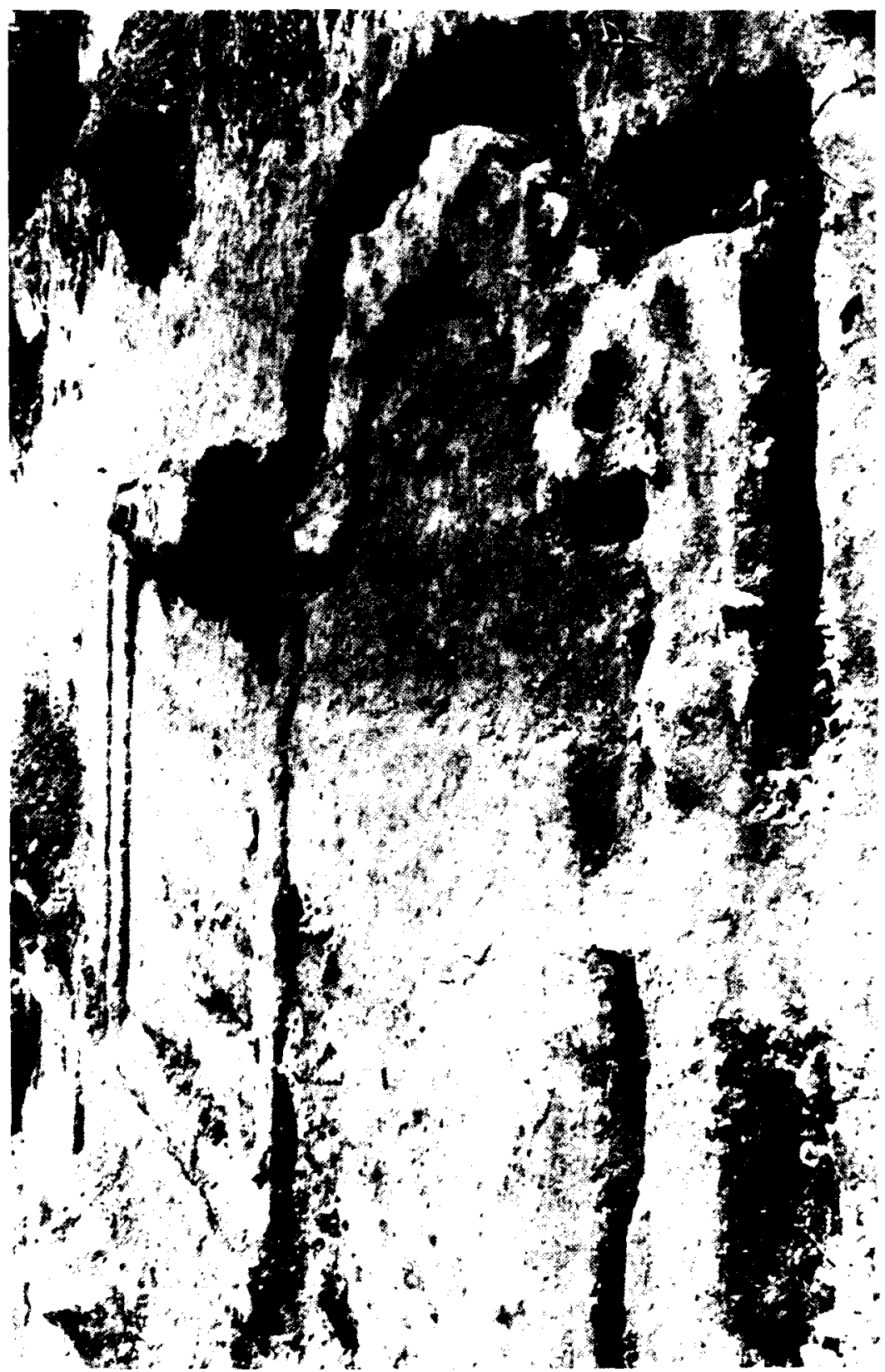

Edificio absidiado (núm. 21) del plano. (V. Renom y L. Mas, 1950) Probable complejo termal. Villa romana de La Salut (Sabadell). 


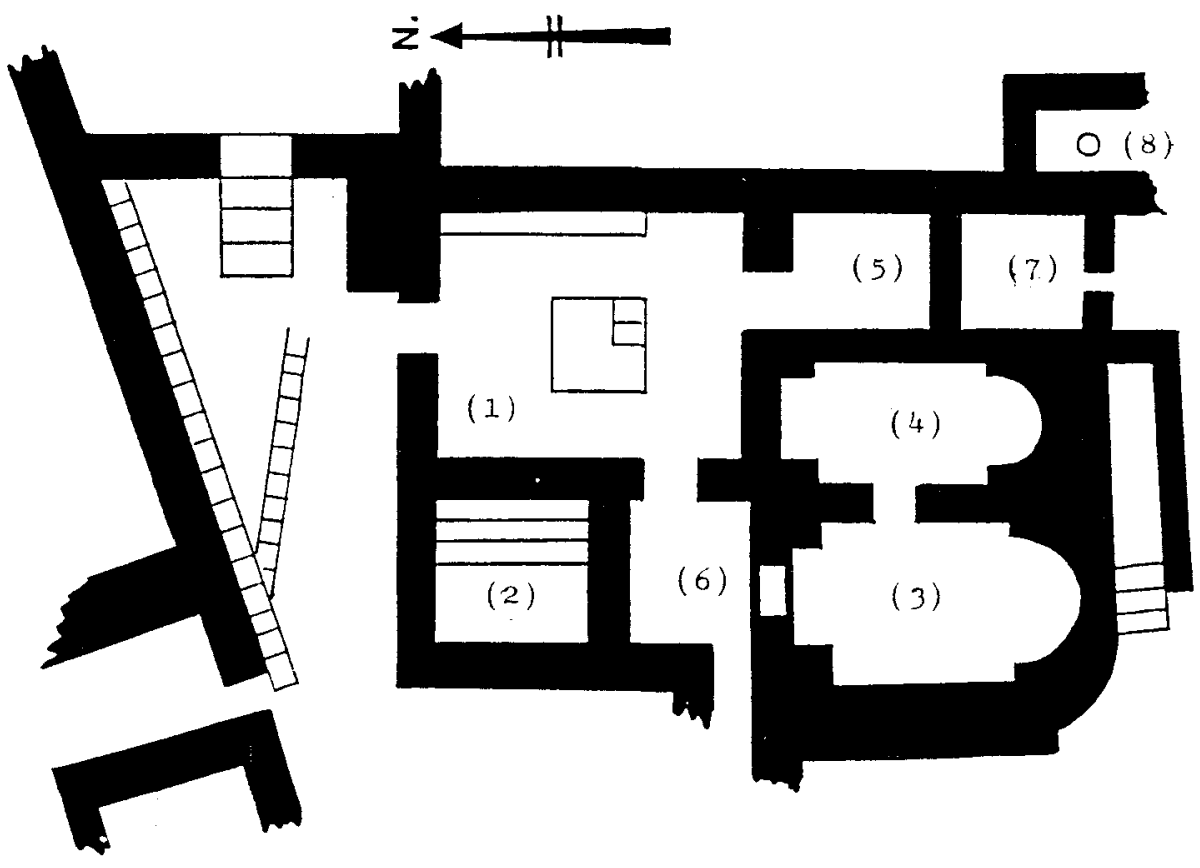

Complejo termal de Can Tarrés: (1) "Frigidarium»; (2) "Frigidarium»; (3) "Laconicum"; (4) "Caldario"; (5) "Tepidarium"; (6) "Fornax"; (7) "Tepidarium" posiblemente en un principio unido al 5; (8) Depósito.

Los puntos 3, 4, 5 y 7 tenian "hipocausto" o "suspensura". 


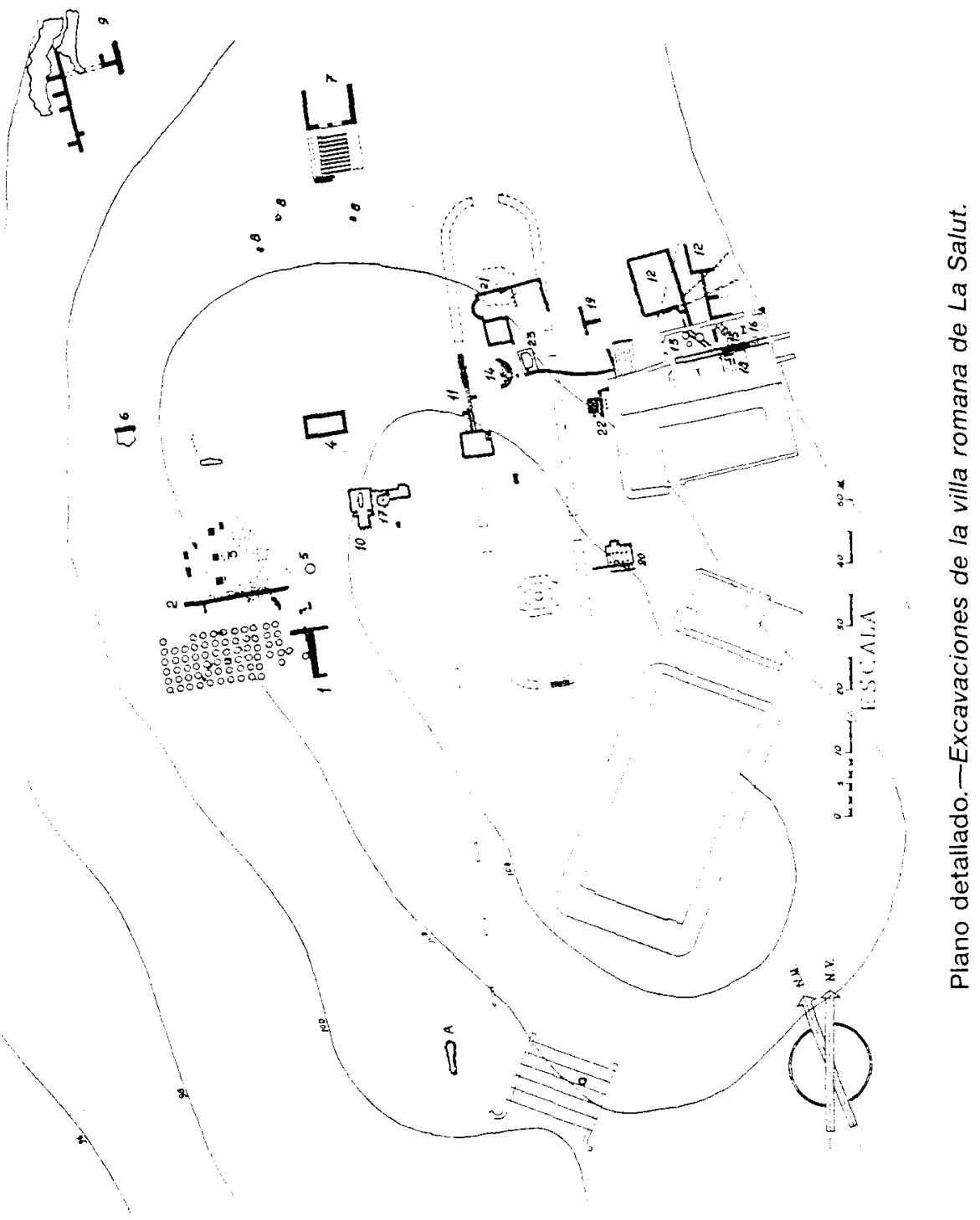

